\title{
Correction to: Dynamic Distribution Adaptation Based Transfer Network for Cross Domain Bearing Fault Diagnosis
}

Yixiao Liao, Ruyi Huang, Jipu Li, Zhuyun Chen and Weihua Li* (D)

\section{Correction to: Chin J Mech Eng (2021) 34:52} https://doi.org/10.1186/s10033-021-00566-3

Following the publication of the original article [1], the authors identified an error in the affiliation.

The correct affiliation is given below:

School of Mechanical \& Automotive Engineering, South China University of Technology, Guangzhou 510641, China.

The original article [1] has been corrected.

\author{
Reference \\ 1. Liao Y, Huang R, Li J, Chen Z, Li W. Dynamic Distribution Adaptation Based \\ Transfer Network for Cross Domain Bearing Fault Diagnosis. Chin. J. Mech. \\ Eng. (2021) 34:52 https://doi.org/10.1186/s10033-021-00566-3
}

Published online: 10 August 2021

The original article can be found online at https://doi.org/10.1186/s10033021-00566-3.

${ }^{*}$ Correspondence: whlee@scut.edu.cn

School of Mechanical \& Automotive Engineering, South China University

of Technology, Guangzhou 510641, China

SpringerOpen

(C) The Author(s) 2021. Open Access This article is licensed under a Creative Commons Attribution 4.0 International License, which permits use, sharing, adaptation, distribution and reproduction in any medium or format, as long as you give appropriate credit to the original author(s) and the source, provide a link to the Creative Commons licence, and indicate if changes were made. The images or other third party material in this article are included in the article's Creative Commons licence, unless indicated otherwise in a credit line to the material. If material is not included in the article's Creative Commons licence and your intended use is not permitted by statutory regulation or exceeds the permitted use, you will need to obtain permission directly from the copyright holder. To view a copy of this licence, visit http://creativecommons.org/licenses/by/4.0/. 